\title{
GERMINAÇÃO DE SEMENTES DE JENIPAPEIRO SUBMETIDAS À PRÉ-EMBẺBIÇÃO EM REGULADOR E ESTIMULANTE VEGETAL
}

\author{
Seed germination of genipap submitted to pre-soaking in regulator and plant stimulante
}

\author{
Manoel Prado Neto', Ana Cristina Vello Loyola Dantas², Elvis Lima Vieira², Vanessa de Oliveira Almeida ${ }^{3}$
}

\begin{abstract}
RESUMO
Objetivou-se avaliar a germinação de sementes e crescimento inicial de plântulas de jenipapo (Genipa americana L.) submetidas à pré-embebição em regulador e estimulante vegetal. Utilizou-se delineamento inteiramente casualizado com quatro repetições de 25 sementes e oito tratamentos, nos quais as sementes foram embebidas por 12 horas em: T1 - água, T2 - Giberelina líquida a 4\% de GA $\left(\mathrm{GA}_{3} 4 \% \mathrm{~L}\right)$ a $50 \mathrm{~mL} \mathrm{~L}^{-1}, \mathrm{~T} 3-\left(\mathrm{GA}_{3} 4 \% \mathrm{~L}\right)$ a $100 \mathrm{~mL} \mathrm{~L}^{-1}, \mathrm{~T} 4-\left(\mathrm{GA}_{3} 4 \% \mathrm{~L}\right)$ a $200 \mathrm{~mL} \mathrm{~L}^{-1}, \mathrm{~T} 5-\left(\mathrm{GA}_{3} 4 \% \mathrm{~L}\right)$ a $300 \mathrm{~mL} \mathrm{~L}^{-1}, \mathrm{~T}^{-}-\left(\mathrm{GA}_{3}\right.$ $4 \% \mathrm{~L}$ ) a $400 \mathrm{~mL} \mathrm{~L}^{-1}$, T7 - Stimulate ${ }^{\circledR}$ a $5 \mathrm{~mL} \mathrm{~L}^{-1}$ e T8 - Stimulate ${ }^{\circledR}$ a $10 \mathrm{~mL} \mathrm{~L}^{-1}$. As sementes foram dispostas sobre folhas de papel toalha previamente umedecidas com água destilada e levadas para o germinador, regulado a $28^{\circ} \mathrm{C}$, avaliando-se porcentagem de germinação, comprimento da raiz, do hipocótilo e total da plântula 21 dias após a semeadura e Índice de Velocidade de Germinação. Não houve efeito da pré-embebição na germinação das sementes com variação entre 89 a $95 \%$. Os resultados obtidos evidenciaram que a pré-embebição de sementes de jenipapo por 12 horas em $4 \% \mathrm{GA}_{3} \mathrm{~L}\left(50,100 \mathrm{e} 200 \mathrm{~mL} \mathrm{~L}^{-1)} \mathrm{e}\right.$ Stimulate ${ }^{\circledR}\left(10 \mathrm{~mL} \mathrm{~L}^{-1}\right)$, proporcionam maiores índices de velocidade de germinação. O Stimulate ${ }^{\circledR} 10 \mathrm{~mL} \mathrm{~L}^{-1}$, em pré-embebição por 12 horas proporciona maiores comprimentos das raízes e total das plântulas de jenipapo em relação aos demais tratamentos.
\end{abstract}

Termos para indexação: Genipa americana, ácido giberélico, Stimulate ${ }^{\circledast}$, crescimento.

\begin{abstract}
This work aimed to evaluate the genipap (Genipa americana L.) seed germination and its initial seedling growth, submitted to pre-soaking in regulator and vegetal stimulant. It was arranged in a randomized design with four repetitions of 25 seeds and eight treatments, in which seeds were impregnated for 12 hours: T1 - water, T2 - Liquid gibberellins $4 \% \mathrm{GA}_{3}\left(\mathrm{GA}_{3} 4 \% \mathrm{~L}\right)\left(50 \mathrm{~mL} \mathrm{~L}^{-1}\right), \mathrm{T} 3$ - $\left(\mathrm{GA}_{3} 4 \% \mathrm{~L}\right)\left(100 \mathrm{~mL} \mathrm{~L}^{-1}\right), \mathrm{T} 4-\left(\mathrm{GA}_{3} 4 \% \mathrm{~L}\right)\left(200 \mathrm{~mL} \mathrm{~L}^{-1}\right), \mathrm{T} 5-\left(\mathrm{GA}_{3} 4 \% \mathrm{~L}\right)\left(300 \mathrm{~mL} \mathrm{~L}^{-1}\right), \mathrm{T} 6-\left(\mathrm{GA}_{3} 4 \% \mathrm{~L}\right)\left(400 \mathrm{~mL} \mathrm{~L}^{-1}\right), \mathrm{T}^{3}-$ Stimulate ${ }^{\circledR}\left(5 \mathrm{~mL} \mathrm{~L}^{-1}\right)$ e T8 - Stimulate ${ }^{\circledR}\left(10 \mathrm{~mL} \mathrm{~L}^{-1}\right)$. The seeds were disposed on a paper, previously wet with distilled water and taken to the germinator chamber adjusted in $28^{\circ} \mathrm{C}$. There were evaluated the germination percentage, roots length, hypocotyls, and seedling 21 days after the seeding and the Germination Velocity Index. The results had shown that the genipap's seed pre-soaking for 12 hours in $\mathrm{GA}_{3} 4 \% \mathrm{~L}\left(50,10\right.$ e $\left.200 \mathrm{~mL} \mathrm{~L}^{-1}\right)$ e Stimulate ${ }^{\circledR}\left(10 \mathrm{~mL} \mathrm{~L}^{-1}\right)$, provides a higher germination velocity index. The Stimulate ${ }^{8}$ $10 \mathrm{~mL} \mathrm{~L}^{-1}$, in pre-soaking for 12 hours provides a higher root growth and increase the number of genipap seedlings, comparing with others treatments.
\end{abstract}

Index terms: Genipa americana, Giberellic Acid, Stimulate ${ }^{\circledR}$, Growth.

(Recebido em 27 de abril de 2006 e aprovado em 20 de outubro de 2006)

\section{INTRODUÇÃO}

Nativo do Brasil, o jenipapeiro (Genipa americana L.), da família Rubiceae, ocorre principalmente nas regiões de clima quente e úmido, desenvolvendo-se bem desde o extremo Norte até São Paulo e Mato Grosso (SANTOS, 1978). É considerada uma espécie de importância econômica, tanto pela utilização dos frutos, como pela sua essência florestal, com grande potencial na recomposição de matas ciliares, produção de madeira para fabricação de cabos de enxada, foice, machado, construção civil, naval etc. (LORENZI, 1992). Adulta é uma árvore ereta, forte, frondosa, podendo alcançar $20 \mathrm{~m}$ de altura (CORRÊA, 1984).
As folhas são curto-pecioladas, opostas, luzidias e as flores são hermafroditas, brancas no princípio e depois se tornam amareladas. Os frutos são do tipo baga sub-globosa, de 8 a $10 \mathrm{~cm}$ de comprimento e 6 a $7 \mathrm{~cm}$ de diâmetro, casca mole, parda ou pardacento-amarelada, membranosa, fina e enrugada. A polpa é sucosa, aromática, comestível, contendo numerosas sementes compridas no centro (DONADIO et al., 1998).

As sementes são fibrosas, albuminadas, castanhoescuras, de $6 \mathrm{~mm}$ a $12 \mathrm{~mm}$, comprimidas e achatadas (CORRÊA, 1984). São anátropas com formato deltóide, bitegumentada, com os tegumentos cobrindo toda a extensão da semente exceto na região da calaza; o

\footnotetext{
Engenheiro Agrônomo, Mestre em Fitotecnia - Escola Federal de Catu - Rua Barão de Camaçari, 118 - $48110-000$ - Catu, BA manoelpradoneto@bol.com.br

Engenheiro Agrônomo, Dr., Centro de Ciências Agrárias, Ambientais e Biológicas - Universidade Federal do Recôncavo da Bahia/CCAAB/UFRB Campus Universitário - 44380-000 - Cruz das Almas, BA - acvld@ufba.br; elvieira@ufba.br

${ }^{3}$ Acadêmica de Agronomia, Centro de Ciências Agrárias - Ambientais e Biológicas - Universidade Federal do Recôncavo da Bahia/CCAAB/UFRB Campus Universitário - 44380-000 - Cruz das Almas, BA - voagro@click21.com.br
} 
tegumento externo é de coloração castanho-escura. O embrião é axial, contínuo, espatulado, com cotilédones foliáceos e fotossintetizantes. A germinação é epígea e as plântulas são fanerocotiledonares (NASCIMENTO \& DAMIÃO-FILHO, 1998).

A propagação do jenipapeiro se dá via sementes e vegetativamente, com predominância da via sexuada. No entanto, assim como acontece com as fruteiras nativas, pouco se conhece sobre as condições ideais para a germinação das sementes de jenipapo. Andrade et al. (2000) apresentam estudo sobre a morfologia da semente e o desenvolvimento pós-seminal, caracterizando a plântula normal e os padrões de anormalidade. Silva et al. (1994) recomendaram imersão das sementes de jenipapo em água a $65^{\circ} \mathrm{C}$ por 5 a 10 minutos para superação da dormência e Nascimento \& Damião-Filho (1998), visando acelerar e uniformizar a germinação, que pode demorar de 15 a 30 dias, recomendaram a imersão das sementes em água fria por 48 horas.

Como forma de acelerar e melhorar a germinação de sementes e também promover o crescimento das plantas jovens, vários pesquisadores preconizaram o uso de reguladores vegetais. Bewley \& Black (1986) reportaram sobre a presença de hormônios na semente, sendo sua ação relacionada com o crescimento do embrião. Dentre os hormônios presentes nas sementes, o de mais largo espectro de atuação são as giberelinas.

As giberelinas possuem efeito estimulatório no processo germinativo quando aplicadas em sementes com dormência e também em não dormentes. As sementes podem necessitar de giberelinas para uma série de eventos: ativação do crescimento vegetativo do embrião, mobilização das reservas do endosperma e no enfraquecimento da camada de endosperma que circunda o embrião, favorecendo assim seu crescimento (TAIZ \& ZEIGER, 1991).

Weaver (1987) relata que a dormência pode ser resultado do balanço hormonal entre promotores e inibidores de crescimento. Da mesma forma, Bryant (1989) e Kigel \& Galili (1995) concordam que a quebra de dormência pode ser realizada pela mudança no balanço hormonal e que o ácido giberélico atua na promoção da germinação. Em sementes de cereais, as giberelinas ativam a síntese de enzimas que irão hidrolisar as reservas da semente, liberando energia para o crescimento do embrião (TAIZ \& ZEIGER, 1991), além de aumentar o alongamento celular, fazendo com que a radícula e a parte área possam desenvolver-se (SALISBURY \& ROSS, 1992). Pinto (1976), trabalhando com sementes de graviola (Annona muricata
L.), obteve $82,1 \%$ de germinação, com o uso de $300 \mathrm{mg} \mathrm{L}^{-1}$ de ácido giberélico, enquanto a testemunha apresentou 75,1\% de germinação. Hernández (1993) relata que o ácido giberélico usado em concentração de $100 \mathrm{mg} \mathrm{L}^{-1}$ promoveu significativo aumento na germinação de (Annona cherimola L.) de 57,25\% (testemunha) para 70,00\%.

Yousif et al. (1989), trabalhando com sementes de laranja 'Azeda' (Citrus aurantium L.), obtiveram uma germinação de $83 \%$, com a aplicação de $50 \mathrm{mg} \mathrm{L}^{-1}$ de $\mathrm{GA}_{3}$, por 6 horas. Leonel et al. (1994) também conseguiram bons resultados com a aplicação de $50 \mathrm{mg} \mathrm{L}^{-1}$ em sementes de Citrus amblycarpa Ochse ( $72 \%$ de germinação), porém os tratamentos com $100 \mathrm{mg} \mathrm{L}^{-1}$ e $250 \mathrm{mg} \mathrm{L}^{-1}$ não se mostraram benéficos, sendo inferiores à testemunha $(68,75 \%$ de germinação).

De acordo com Ferreira et al. (1997), a aplicação de $200 \mathrm{mg} \mathrm{L}^{-1}$ de $\mathrm{GA}_{3}$ promoveu considerável aumento da germinação de sementes de Annona squamosa L. em condições de câmara de germinação com temperatura alternada entre 20 e $30^{\circ} \mathrm{C}$.

Para Bryant (1989), a quebra da dormência é ocasionada por mudança no balanço entre substâncias inibidoras de crescimento da planta, como o ácido abscísico (ABA), e substâncias promotoras de crescimento como o $\left(\mathrm{GA}_{3}\right)$. Isto poderia ocorrer devido ao decréscimo na quantidade de $\mathrm{ABA}$, ou acréscimo na quantidade de $\mathrm{GA}_{3}$ ou, ainda, devido a ambos. Entretanto, o autor enfatiza que o mecanismo pelo qual as substâncias de crescimento induzem ou quebram a dormência não é na realidade conhecido.

A mistura de dois ou mais reguladores vegetais ou de reguladores vegetais com outras substâncias (aminoácidos, nutrientes, vitaminas) é designada de bioestimulante ou estimulante vegetal. Esse produto químico pode incrementar o crescimento e desenvolvimento vegetal estimulando a divisão celular, diferenciação e o alongamento das células, podendo também, aumentar a absorção e a utilização de água e dos nutrientes pelas plantas (VIEIRA, 2001).

Neste trabalho, objetivou-se avaliar a germinação de sementes e crescimento inicial de plântulas de jenipapo submetidas à pré-embebição em regulador e estimulante vegetal.

\section{MATERIAL E MÉTODOS}

O ensaio foi instalado no Laboratório de Fisiologia Vegetal do Centro de Ciências Agrárias e Ambientais da Universidade Federal da Bahia. As sementes foram obtidas de frutos maduros mediante lavagem em água corrente $\mathrm{e}$ 
secagem à sombra por três dias. $\mathrm{O}$ teor de umidade das sementes foi determinado pelo método de estufa a $105^{\circ} \mathrm{C}$ por 24 horas (BRASIL, 1992), obtendo-se umidade média de $35 \%$. Utilizou-se delineamento inteiramente casualizado com quatro repetições de 25 sementes e oito tratamentos, nos quais as sementes foram embebidas por 12 horas em: T1 - controle (água destilada), T2 - giberelina líquida com 4 $\%$ de ácido giberélico $\left(\mathrm{GA}_{3} 4 \% \mathrm{~L}\right)$ a $50 \mathrm{~mL} \mathrm{~L}^{-1}, \mathrm{~T} 3-\left(\mathrm{GA}_{3} 4 \%\right.$ L) a $100 \mathrm{~mL} \mathrm{~L}^{-1}, \mathrm{~T} 4-\left(\mathrm{GA}_{3} 4 \% \mathrm{~L}\right)$ a $200 \mathrm{~mL} \mathrm{~L}^{-1}, \mathrm{~T} 5-\left(\mathrm{GA}_{3} 4 \%\right.$ L) a $300 \mathrm{~mL} \mathrm{~L}^{-1}, \mathrm{~T} 6-\left(\mathrm{GA}_{3} 4 \% \mathrm{~L}\right)$ a $400 \mathrm{~mL} \mathrm{~L}^{-1}, \mathrm{~T} 7$ - Stimulate $^{\circledR}$ a $5 \mathrm{~mL} \mathrm{~L}^{-1}$ e T8 - Stimulate $^{\circledR}$ a $10 \mathrm{~mL} \mathrm{~L}^{-1}$. O GA $4 \%$ Lé um regulador vegetal líquido à base de ácido giberélico $(4 \%) \mathrm{e}$ $96 \%$ de ingredientes inertes e o Stimulate ${ }^{\circledR}$ é um estimulante vegetal composto por três reguladores vegetais $(0,009 \%$ de cinetina, 0,005\% de ácido giberélico, 0,005\% de ácido indolbutírico e 99,98\% de ingredientes inertes (STOLLER DO BRASIL, 1998).

As sementes foram dispostas sobre folhas de papel toalha previamente umedecidas com água destilada e levadas para o germinador, regulado a $28^{\circ} \mathrm{C}$, avaliando-se porcentagem de germinação $(\% \mathrm{G})$, comprimento da raiz $(\mathrm{CR})$ do hipocótilo $(\mathrm{CH})$ e total da plântula (CTP) 21 dias após a semeadura (DAS) e índice de velocidade de germinação (IVG), conforme fórmula de Maguire (1962), apresentada por Borghetti \& Ferreira (2004). Os dados foram submetidos à análise de variância, comparação de médias pelo teste de Tukey a 5\% de probabilidade para todos os tratamentos e análise de regressão para os tratamentos T1, T2, T3, T4, T5 e T6, visando verificar a ação isolada da Giberelina Líquida sobre os parâmetros observados. Não houve necessidade de transformação dos dados para atendimento das preposições da análise da variância.

\section{RESULTADOS E DISCUSSÃO}

A pré-embebição por $12 \mathrm{~h}$ em água destilada, giberelina líquida $\left(\mathrm{GA}_{3} 4 \% \mathrm{~L}\right)$ ou Stimulate ${ }^{\circledR}$ nas doses avaliadas, não apresentaram efeito significativo sobre a germinação de sementes e comprimento do hipocótilo de plântulas de jenipapo, sendo que esses parâmetros variaram de 89 a $95 \%$ e 14,40 a 18,32 mm, respectivamente (Tabela 1). Sementes de algodoeiro também não responderam ao uso de Stimulate ${ }^{\circledR}$ em doses de até $21 \mathrm{~mL}$, conforme verificado por Santos \& Vieira (2005). No entanto, a embebição em $\left(\mathrm{GA}_{3} 4 \% \mathrm{~L}\right)$, nas doses de 50, 100 e $200 \mathrm{~mL} \mathrm{~L}^{-1}$ e em Stimulate ${ }^{\circledR}$ a $10 \mathrm{~mL} \mathrm{~L}^{-1}$ proporcionaram aumento significativo do Índice de Velocidade de Germinação (IVG), indicando efeito positivo destas substâncias na melhoria do desempenho das sementes, dependendo da dosagem utilizada (Tabela 1).

O melhor resultado quanto ao comprimento de raiz e comprimento total das plântulas foi observado no tratamento com Stimulate ${ }^{\circledR}$ a $10 \mathrm{~mL} \mathrm{~L}^{-1}$, cujas médias superaram o tratamento controle em 84,31 e 46,36\%, respectivamente.

O Stimulate ${ }^{\circledR}$ apresenta um efeito sinergético, em função da presença equilibrada dos reguladores de crescimento. Provavelmente, este efeito foi o responsável pelos melhores resultados obtidos nas variáveis observadas em relação aos outros tratamentos.

$\mathrm{O}$ efeito do Stimulate ${ }^{\circledR}$ no alongamento celular foi verificado por Vieira \& Castro (2001), trabalhando com

TABELA 1 - Porcentagem de germinação (\%G), índice de velocidade de germinação (IVG), comprimento do hipocótilo $(\mathrm{CH})$, comprimento de raiz (CR) e comprimento total de plântula (CTP) de jenipapo provenientes de sementes submetidas a tratamentos de pré-embebição por 12 horas. Cruz das Almas-BA, 2005.

\begin{tabular}{lccccc}
\hline \multicolumn{1}{c}{ Pré -Embebição } & \% G & IVG & CH (mm) & CR (mm) & CTP (mm) \\
\hline Água destilada & $91 \mathrm{a}$ & $2,16 \mathrm{~b}$ & $17,72 \mathrm{a}$ & $20,78 \mathrm{c}$ & $38,50 \mathrm{c}$ \\
$\mathrm{GA}_{3} 4 \% \mathrm{~L} 50 \mathrm{~mL} \mathrm{~L}^{-1}$ & $91 \mathrm{a}$ & $2,31 \mathrm{a}$ & $17,60 \mathrm{a}$ & $26,42 \mathrm{~b}$ & $44,02 \mathrm{~b}$ \\
$\mathrm{GA}_{3} 4 \% \mathrm{~L} 100 \mathrm{~mL} \mathrm{~L}^{-1}$ & $95 \mathrm{a}$ & $2,54 \mathrm{a}$ & $18,32 \mathrm{a}$ & $26,27 \mathrm{~b}$ & $44,60 \mathrm{~b}$ \\
$\mathrm{GA}_{3} 4 \% \mathrm{~L} 200 \mathrm{~mL} \mathrm{~L}^{-1}$ & $95 \mathrm{a}$ & $2,38 \mathrm{a}$ & $17,38 \mathrm{a}$ & $27,60 \mathrm{~b}$ & $44,97 \mathrm{~b}$ \\
$\mathrm{GA}_{3} 4 \% \mathrm{~L} 300 \mathrm{~mL} \mathrm{~L}^{-1}$ & $95 \mathrm{a}$ & $2,28 \mathrm{~b}$ & $16,62 \mathrm{a}$ & $20,55 \mathrm{c}$ & $37,18 \mathrm{c}$ \\
$\mathrm{GA}_{3} 4 \% \mathrm{~L} 400 \mathrm{~mL} \mathrm{~L}^{-1}$ & $91 \mathrm{a}$ & $2,15 \mathrm{~b}$ & $16,12 \mathrm{a}$ & $20,42 \mathrm{c}$ & $36,55 \mathrm{c}$ \\
Stimulate $^{\circledR} 5 \mathrm{~mL} \mathrm{~L}^{-1}$ & $89 \mathrm{a}$ & $2,15 \mathrm{~b}$ & $14,40 \mathrm{a}$ & $22,57 \mathrm{c}$ & $36,98 \mathrm{c}$ \\
Stimulate $^{\circledR} 10 \mathrm{~mL} \mathrm{~L}^{-1}$ & $91 \mathrm{a}$ & $2,38 \mathrm{a}$ & $18,05 \mathrm{a}$ & $38,30 \mathrm{a}$ & $56,35 \mathrm{a}$ \\
\hline \multicolumn{1}{c}{$\mathrm{CV} \%$} & 4,68 & 5,50 & 11,47 & 14,49 & 10,98 \\
\hline
\end{tabular}

Médias seguidas de mesma letra na coluna não diferem entre si pelo teste de Tukey a 5\% de probabilidade. 
sementes de soja (Glycine Max (L). Merril cv. IAC - 8-2). Concentração de $1,3 \mathrm{~mL}$ por $0,5 \mathrm{~kg}$ de sementes favoreceu o crescimento radicular vertical com incremento de $9,9 \%$, em relação ao controle. Resultado semelhante foi observado em algodão cv. CNPAITA 90, onde a aplicação de Stimulate ${ }^{\circledR}$ a 8,5 $\mathrm{mL} 0,5 \mathrm{~kg}^{-1}$ de sementes promoveu um crescimento radicular vertical superior em 13,6 \% em relação ao controle (VIEIRA \& SANTOS, 2005). Vieira (2001), estudando a ação do Stimulate ${ }^{\circledR}$ em sementes de arroz e feijão, observou que o comprimento total do sistema radicular foi superior em $37,7 \%$ para a dose de 2,3 mL de Stimulate ${ }^{\circledR}$ nas plantas de arroz e $19,8 \%$ para a dose de 5,0 mL de Stimulate ${ }^{\circledR} 0,5 \mathrm{~kg}^{-1}$ de sementes, no feijoeiro.

Reghin et al. (2000), em trabalho realizado com mandioquinha-salsa (Arracacia xanthorriza Bancroft), constataram efeito significativo do Stimulate ${ }^{\circledR}$ no número e comprimento de raízes de acordo com o aumento da dose, até o limite de 7,0 $\mathrm{mL} \mathrm{L}^{-1}$, indicando o bioestimulante ser estimulador do crescimento e desenvolvimento radicular.

As giberelinas aumentam a elongação e a divisão celular, o que é evidenciado pelo aumento do comprimento da célula e do número de células (TAIZ \& ZEIGER, 1991). Segundo Sauter \& Kende (1992), esta resposta com um maior crescimento inicial, baseia-se na elongação das células do meristema intercalar, que ao aumentar de tamanho promovem a divisão celular. Assim, as maiores taxas de crescimento são observadas pelo aumento na formação de novas células e pela maior elongação celular em resposta à giberelina.

Avaliando-se separadamente o $\mathrm{GA}_{3} 4 \%$ Formulação Líquida $\left(50,100,200,300\right.$ e $\left.400 \mathrm{~mL} \mathrm{~L}^{-1}\right)$ e o controle, verificase que o regulador à base de ácido giberélico foi eficiente na promoção de maiores Índices de Velocidade de Germinação -IVG (2,21) para a dose estimada de $208,3 \mathrm{~mL} \mathrm{~L}^{-1}$ (Figura 1), comprimento de raiz - CR $\left(27,8 \mathrm{~mm}\right.$ ) para 227,5 $\mathrm{mL} \mathrm{L}^{-1}$ (Figura 2) e comprimento total de plântulas de jenipapo-CTP $(43,2$ $\mathrm{mm}$ ) para a dosagem de $117,0 \mathrm{~mL} \mathrm{~L}^{-1}$ (Figura 2).

A partir dos pontos de máximo (Figuras 1 e 2) observa-se um decréscimo nas variáveis IVG, CR e CTP atingindo valores mínimos na dose de $400 \mathrm{~mL} \mathrm{~L}^{-1}$. Provavelmente, concentrações elevadas de $\mathrm{GA}_{3}$ provocaram algum efeito inibitório no alongamento celular, fato observado na cultura do algodoeiro por Vieira \& Santos (2005).

A presença do ácido giberélico certamente concorreu para a promoção da velocidade de germinação e conseqüentemente maiores Índices de Velocidade de Germinação, como também para o alongamento celular o que proporcionou plântulas com raízes e comprimento total maiores, em relação ao controle.

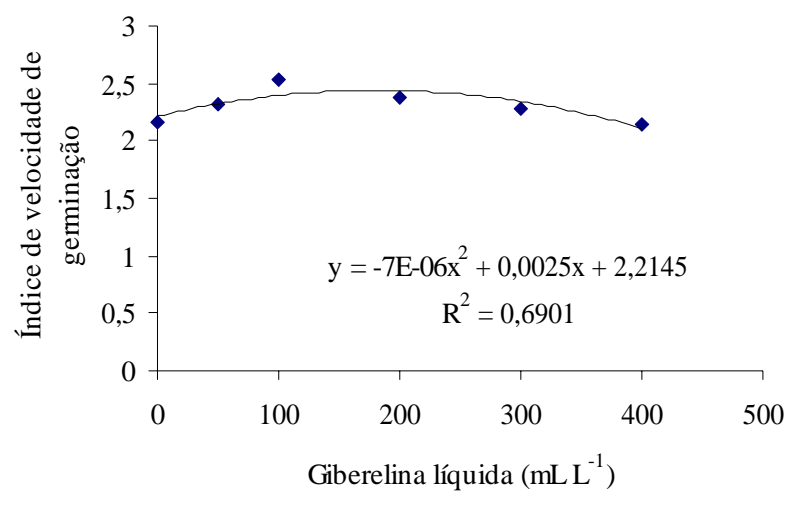

FIGURA 1 - Índice de velocidade de germinação de sementes de jenipapo submetidas à pré-embebição em Giberelina Líquida (4\% $\left.\mathrm{GA}_{3}\right)$.

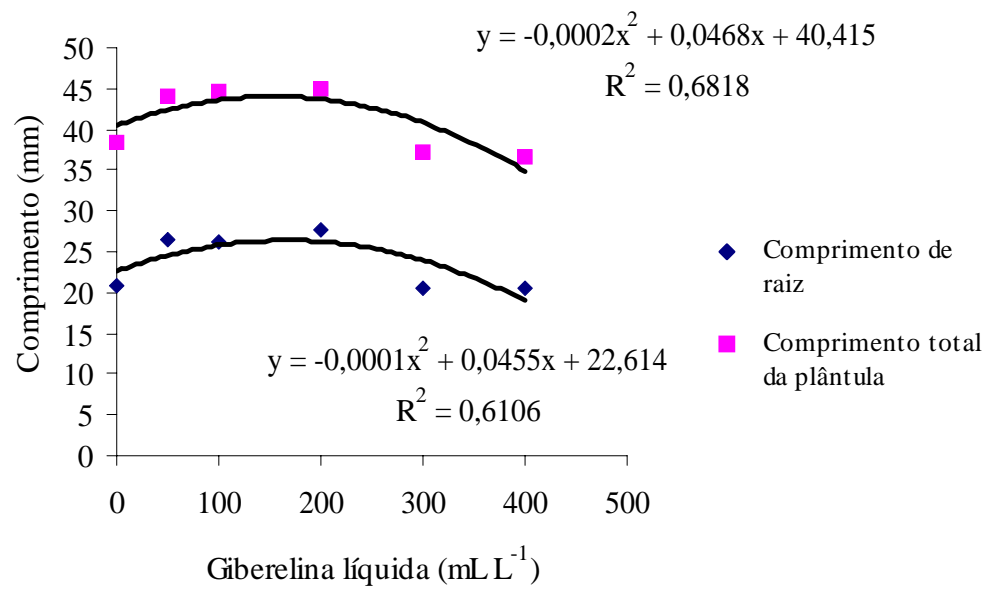

FIGURA 2 - Comprimento de raiz e total de plântulas de jenipapo submetidas à pré-embebição em Giberelina Líquida (4\% GA $)$.

Ciênc. agrotec., Lavras, v. 31, n. 3, p. 693-698, maio/jun., 2007 


\section{CONCLUSÕES}

A pré-embebição de sementes de jenipapo por 12 horas em Giberelina Líquida (4\% GA $)$ nas dosagens de 50, 100 e $200 \mathrm{~mL} \mathrm{~L}^{-1}$ e Stimulate ${ }^{\circledR}$ a $10 \mathrm{~mL} \mathrm{~L}^{-1}$, proporcionam maiores Índices de Velocidade de Germinação.

Maiores comprimentos de raízes e de plântulas de jenipapo podem ser obtidos com o uso de Stimulate $^{\circledR}$ a 10 $\mathrm{mL} \mathrm{L}^{-1}$ em pré-embebição das sementes por 12 horas.

\section{REFERÊNCIAS BIBLIOGRÁFICAS}

ANDRADE, A. C. S. de et al. Germinação de sementes de jenipapo: temperatura, substrato e morfologia do desenvolvimento pós-seminal. Pesquisa Agropecuária Brasileira, Brasília, v. 35, n. 3, mar. 2000.

BEWLEY, J. D.; BLACK, M. Seeds: physiology of development and germination. New York: Plenum, 1986. 367 p.

BORGHETTI, F.; FERREIRA, A. G. Interpretação de resultados de germinação. In: FERREIRA, A. G.; BORGHETTI, F. (Orgs.). Germinação: do básico ao aplicado. Porto Alegre: Artmed, 2004. p. 209-222.

BRASIL. Ministério da Agricultura e Reforma Agrária. DNPV. Divisão de Sementes e Mudas. Regras para análise de sementes. Brasília, DF, 1992. 365 p.

BRYANT, J. A. Fisiologia da semente. São Paulo: EPU, $1989.86 \mathrm{p}$.

CORRÊA, M. P. Jenipapeiro. In: . Dicionário das plantas úteis do Brasil e das exóticas cultivadas. Rio de Janeiro: Imprensa nacional, 1984. p. 515-520.

DONADIO, L. C.; NACHTIGAL, J. C.; SACRAMENTO, C. R. do. Frutas exóticas. Jaboticabal: Funep, 1998. 278 p.

FERREIRA, G.; CEREDA, E.; SILVA, C. P.; CUNHA, R. J. P.; CATANEO, A. Imbibition study of sugar apple (Annona squamosa L.) and atemoya (Annona squamosa L. X A. Cherimola Mill.) sedes. In: CONGRESO INTERNACIONAL DE ANONACEAS, 1997, Chapingo, México. Memórias... Chapingo: Universidade Autônoma Chapingo, 1997. p. 210-224.

HERNÁNDEZ, L. V. La reproducción sexual y multiplicación vegetativa de la annonaceas. Xalapa: Universidad Veracruzana, 1993. 35 p.
KIGEL, J.; GALILI, G. Seed development and germination. 2. ed. New York: Plenum, 1995. 853 p.

LEONEL, S.; MODESTO, J. C.; RODRIGUES, J. D. Influência de fitorreguladores e nitrato de potássio na germinação de sementes e no crescimento de porta-enxertos de Citrus amblycarpa. Science in Agricultura, Piracicaba, v. 51, p. 252-259, 1994.

LORENZI, H. Árvores brasileiras: manual de identificação e cultivo de plantas arbóreas nativas do Brasil. Nova Odessa: Plantarum, 1992. 352 p.

MAGUIRE, J. D. Speed of germination aid in selection and evaluation for emergence and vigour. Crop Science, Madison, v. 2, p. 176-177, 1962.

NASCIMENTO, W. N. O. do; DAMIÃO-FILHO, C. F. Caracterização morfológica de sementes e plântulas de jenipapeiro (Genipa americana L-RUBIACEAE). Revista Brasileira de Sementes, Brasília, v. 20, n. 1, p. 143-147, 1998.

PINTO, A. C. Q. Influência de hormônio sobre o poder germinativo de sementes de graviola. In: CONGRESSO BRASILEIRO DE FRUTICULTURA, 1976, Rio de Janeiro. Anais... Rio de Janeiro: Sociedade Brasileira de Fruticultura, 1976. p. 415-420.

REGHIN, M. Y.; OTTO, R. F.; SILVA, J. B. C. "Stimulate® Mo" e proteção com tecido "não tecido" no préenraizamento de mudas de mandioquinha-salsa. Horticultura Brasileira, Brasília, v. 18, n. 1, p. 53-56, 2000.

SALISBURY, F. B.; ROSS, C. W. Plant physiology. 4. ed. California: Wadsworth, 1992. 682 p.

SANTOS, C. M. G.; VIEIRA, E. L. Efeito de bioestimulante na germinação de sementes, vigor de plântulas e crescimento inicial do algodoeiro. Magistra, Cruz das Almas, v. 17, n. 3, p. 124-130, 2005.

SANTOS, J. B. dos. Jenipapo. In: MAGALHÃES, A.; BOLDINI, M. da G. Grande manual globo de agricultura, pecuária e receituário industrial. Porto Alegre: Globo, 1978. v. 3, p. 234-236.

SAUTER, M.; KENDE, H. Gibberellin-induced growth and regulation of the cell division cycle in deepwater rice. Planta, Jaboticabal, v. 188, p. 362-368, 1992. 
SILVA, L. M. M.; MATOS, V. P.; LiMA, A. A. Tratamentos pré-germinativos para superar a dormência de sementes de jenipapo (Genipa americana). In: CONGRESSO BRASILEIRO DE FRUTICULTURA, 13., 1994, Salvador. Resumos... Salvador: SBP, 1994. p. 10811082.

STOLLER DO BRASIL. Stimulate ${ }^{\circledR}$ Mo em hortaliças: informativo técnico. Cosmópolis: Stoller do Brasil-Divisão Arbore, 1998.

TAIZ, L.; ZEIGER, E. Ethylene and abscisic acid. In: Plant physiology: redwood city. Washington: Cummings, 1991. p. 482-487.

VIEIRA, E. L. Ação de bioestimulante na germinação de sementes, vigor de plântulas, crescimento radicular $\mathrm{e}$ produtividade de soja (Glycine $\max (L$.) Merrill), feijoeiro (Phaseolus vulgaris L.) e arroz (Oriza sativa L.). 2001. 122 p. Tese (Doutorado em Fitotecnia) - Escola Superior de
Agricultura "Luiz de Queiroz", Universidade de São Paulo, Piracicaba, 2001.

VIEIRA, E. L.; CASTRO, P. R. C. Ação de bioestimulante na germinação de sementes, vigor de plântulas, crescimento radicular e produtividade de soja. Revista Brasileira de Sementes, Brasília, v. 23, n. 2, 2001.

VIEIRA, E. L.; SANTOS, C. M. G. Efeito de bioestimulante no crescimento e desenvolvimento inicial de plantas de algodoeiro. Magistra, Cruz das Almas, v. 17, n. 3, p. 124130, set./dez. 2005.

WEAVER, R. J. Reguladores del crecimiento de las plantas en la agricultura. 5. ed. Mexico: Trillas, 1987. 622 p.

YOUSIF, Y. H.; HASSAN, K.; AL-SAADOON, H. S. Effect of giberellic acid on germination of sour orange seeds and their growth in ten soils mixes. Annals of Agricultural Science, [S.1.], v. 34, p. 1139-1149, 1989. 